Theoret. Chim. Acta (Berl.) 33, 351 (1974)

(C) by Springer-Verlag 1974

\title{
Erratum
}

\section{A Remark on the Comparison between the Roothaan Open Shell and Half-Electron Method}

\author{
P. Č́rsky and R. Zahradník
}

Theoret.Chim. Acta (Berl.) 26, 171 (1972)

Received January 23, 1974

We found a minor error in our computer program which brings about an incorrect evaluation of coulomb $J_{m m}$ integrals in some cases. Two lines in Table 3 should be corrected as follows:

Table 3. Total $\mathrm{CNDO} / 2$ energies for systems having a non-degenerate singly occupied molecular orbital. (All entries are in $\mathrm{eV}$.)

\begin{tabular}{llll}
\hline Radical & LHP & $\mathrm{R}$ & Difference \\
\hline $\mathrm{BH}_{2}$ & -134.488 & -134.493 & 0.005 \\
$\mathrm{NO}_{2}$ & -1317.623 & -1317.632 & 0.009 \\
\hline
\end{tabular}

As the corrected values differ rather little from the original ones, no alternation of the discussion is needed. The same holds about the subsequent Erratum.

Dr. P. Ćársky

Dr. R. Zahradnik

J. Heyrovský Institute of Physical Chemistry and Electrochemistry

7 Máchova

Prague 2 - Vinohrady

Czechoslovakia 